\section{Gnomic genomes}

\section{Joseph F. Sambrook}

Genes and Genomes. By Maxine Singer and Paul Berg. Blackwell/University Science Books: 1990. Pp. 929. Hbk £49.50, \$52; pbk £27.50.

IN March 1960. Frances Partridge, the last survivor of the original Bloomsbury group of literary and artistic figures, went to dimner in Golder's Green at the house of the distinguished geneticist. Lionel Galton. Frances Partridge's diary : ( Hanging On: Diaries 1960-1963, Collins. $1990)$ describes her reaction to viewing preparations of human chromosomes through an elegant light microscope that Galton kept at home.

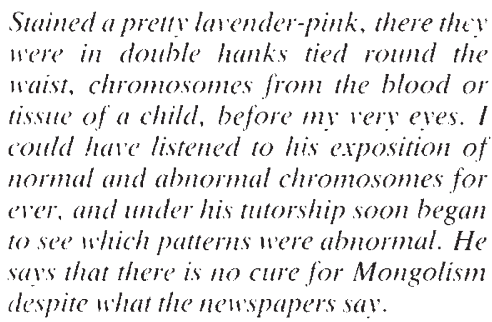

Suined a preaty lavender-pink, there the were in double hanks tied round the waist, chromosomes from the blood of tissue of a child, before my verveves. I could have listened to his exposition of normal and abnormal chromosomes for 'rer, and under his tutorship soon began to see which patterns were abnormal. He savs that there is no cure for Mongolism despite what the newspapers say.

After 60 years of hard training in leftwing aesthetics, it is not surprising that Frances Partridge should so clearly appreciate the delicate beauty of these objects while fretting about the starkness of the message that they carried.

Frances Partridge is now over 90 years old. Despite remaining disappointed that Down's syndrome cannot yet be cured and that its etiology is still not understood at the molecular level, she almost certainly would be delighted by the elegance and intellectual depth of the work on chromosomal organization and function that has been accomplished in the 30 years since she dined with Galton. Only a small fraction of this work has been assimilated into standard textbooks and Genes and Genomes is the first serious attempt to present an integrated and comprehensive view of chromosomes at the molecular level to graduate students and undergraduates.

Berg and Singer's book has a strong sense of the history of molecular genetics of eukaryotes. Scientific topics are often discussed in a chronological manner. usually taking the analogous situation in prokaryotes as a starting point. This approach serves the authors well while they are dealing with the early discoveries of eukaryotic molecular biology, but becomes rather strained when no obvious prokaryotic model is available. For example, the experiments on the structure of adenovirus messenger RNAs, which opened the way to the discovery of split

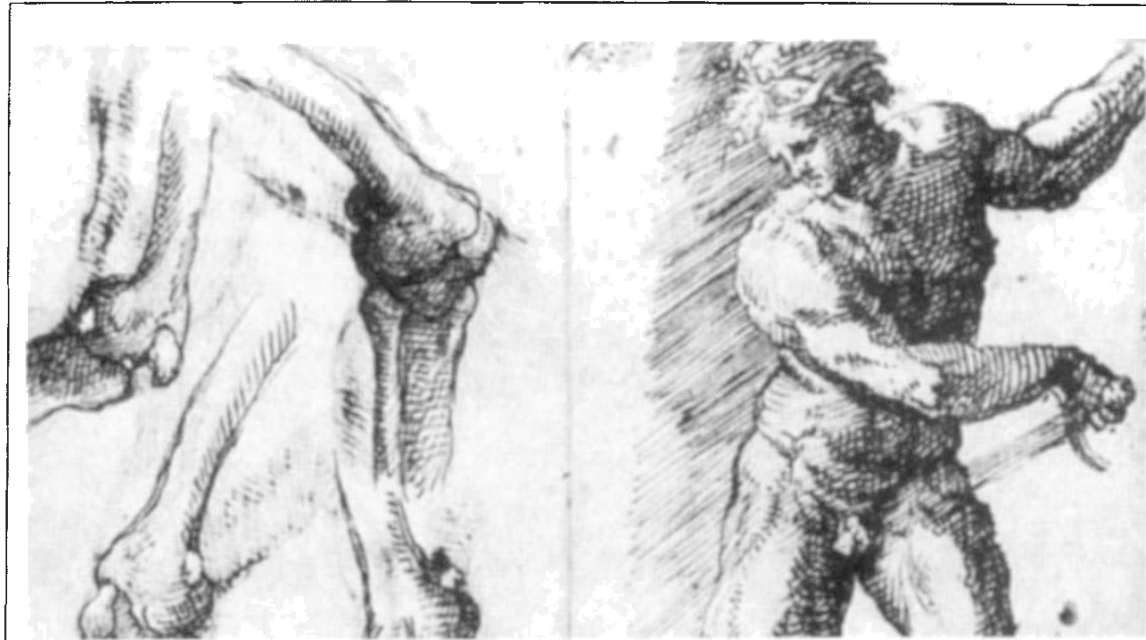

Inigo Jones's Italian sketch book taken from Early Lithographed Books by Michael Twyman and published by Farrand Press/The Book Press at $£ 48.50, \$ 87.50$.

eukaryotic genes and RNA splicing and had such profound consequences for the subsequent development of eukaryotic molecular biology, are described only in the most general terms - presumably because they then had no precedent in prokaryotic biology. The authors" views of the seminal events of the last 20 years are highly personal and inevitably reflect their own scientific interests and involvements. For example, more space is given to the design of eukaryotic viral vectors (12 pages) than to transgenic animals (two paragraphs); and the preface contains an extended account of the events of the mid 1970 s that led to the establishment and subsequent lifting of the moratorium on recombinant DNA research in the United States. While this may stand as a sociological milestone, it was essentially a nonevent in scientific terms and has little relevance to today's students.

The book is divided into four sections. which are successful to different extents Part one is an elementary introduction to molecular biology that is intended for readers with only limited prior knowledge of biochemistry, cell biology and genetics. Part two describes some of the laboratory techniques used in molecular cloning. This section may be of help to people who have no previous exposure to recombinant DNA technology, but it gives no indication of the strengths and weaknesses of the various methods and in many places is quite seriously out-of-date. Part three is by far the most substantial section of the book; its 400 pages contain an excellent and lucid description of the general organization of chromosomes, of gene structure and the regulation of gene expression and of the nature and significance of moveable genetic elements and genomic rearrangements. These topics are treated in greater depth and with more insight than in any other undergraduate and graduate text currently available. Genes and Genomes is worth its purchase price for the excellence of part three alone. The final section of the book is less successful. The authors cram into 50 pages, descriptions of a large number of complex biological systems, including differential gene expression, restriction mapping of large genomes, generation and use of transgenic animals, embryological development, insertional mutagenesis. molecular virology and so on. The necessarily superficial treatment afforded to each of these topics stands in sharp contrast to the well-balanced excellence of part three. Graduate students who have read the book bewail the absence of problem sets, the omission of page numbers from cross-references and the lack of annotations in the long list of key references that are given at the end of each of the four major sections. It is not alwavs obvious to students why many of these references are included nor why others are omitted. A one-sentence description of the scientific kernel of each paper would be extremely useful.

Throughout the book, the authors are at their best when dealing with genomes from the bottom up and, as a consequence, the reader is left with the impression that most, if not all, problems of genome structure and genetic behaviour can be solved by analysis of individual genes. Because this approach suffers from both theoretical and technical limitations, I hope that future editions of Genes and Genomes will include more detailed descriptions of 'top-down' methods of genomic analysis, and will describe how data obtained from analysis of linkage and segregation of genetic markers can be reconciled with physical maps of chromosomes. A book about genes and genomes that does not do justice to classical genetics misses the central issue that Frances Partridge grasped so clearly in 1960.

Joseph F. Sambrook is in the Department of Biochemistry. The University of Texas, Southwestern Medical Center at Dallas, 5323 Harry Hines Boulevard, Dallas, Texas 75235-9038. USA. 